\title{
The effect of long-distance running on bone strength and bone biochemical markers
}

\author{
Jong Hwa Lee* \\ Department of Physical Medicine and Rehabilitation, Dong-A University College of Medicine, Busan, Korea
}

It still remains controversial whether exercise will help or adversely affect the bone formation. The aim of this study was to evaluate the effect of common long-distance running on the magnitude of change in bone properties as measured by quantitative ultrasound (QUS) and bone biochemical markers. Subjects included 68 long-distance runners and 40 controls. Long-distance runners had been training in the marathon club for at least 6 months, the average period of exercise was 2 years, and running at $48.6 \pm 24.9 \mathrm{~km}$ per week. Otherwise, controls were people who had not experienced any specific sports before. Bone speed of sound (SOS) was measured by QUS at the distal one third radius and the mid-shaft of the tibia. Serum osteocalcin and urine deoxypyridinolin

\section{INTRODUCTION}

The running population is on the rise, especially in the size of marathon clubs and the hosting of official marathon events. Some of the reasons for the recent increase in the marathon include increased urban population and income, concerns about obesity and a lack of exercise, and a tendency toward health and quality of life. Running is easy to do anytime, anywhere, requires no special equipment and skills, and a typical aerobic workout is also an important reason for the population's growth. As interest in marathons increases, various studies have been conducted on how long-distance running affects the body. Various studies have been reported on changes in hormones, electrolytes, metabolites, and metabolic rates, especially before and after exercise (Kyröläinen et el., 2000; Westerterp et al., 1992). However, while studies on exercise and bone metabolism show that regular weight load exercises maintain or enhance bone density (Aloia et al., 1978; Williams et al., 1984), some studies are rather confusing because they were measured in all groups. No significant differences were found in tibial and radial SOS between the two groups. Serum osteocalcin was higher in long-distance runners than control $(P<0.05)$ in both the 30s and 40 s of the participants, but urine deoxypyridinolin showed no significant difference between the two groups. It is concluded that long-distance running at the club level increases bone formation marker, but seems to do no harmful effect on bone properties as measured by QUS.

Keywords: Long-distance runners, Speed of sound, Osteocalcin, Deoxypyridinolin
${ }^{*}$ Corresponding author: Jong Hwa Lee (D) https://orcid.org/0000-0003-2489-358X Department of Physical Medicine and Rehabilitation, Dong-A University College of Medicine, 26 Daesingongwon-ro, Seo-gu, Busan 49201, Korea E-mail: jhlee08@dau.ac.kr

Received: November 8, 2018 / Accepted: January 15, 2019 report contrasting results (Lindberg et al., 1984; Warren et al., 1991). Michel et al. (1989) found that moderate exercise increases bone mass using dual energy radiation absorption. Another study by Hetland et al. (1993) reported that weight-bearing exercise had a reduced bone density effect in bones with high rates of trabecular excluding the spine. In addition, a study on the effects of long-distance running on men reported reduced bone density and the negative correlation between lumbar spine density and distance per week (Hetland et al., 1993). There have been reports that running long-distances not only temporarily suppresses bone formation but also stimulates bone absorption (Brahm et al., 1997). Other study suggested that the concentration of parathyroid hormones increased during endurance exercises (Franck et al., 1991). According to these theories, the more often you run long-distances, the less bone density you lose.

In this study, our purpose was to find out how long-distance running affected the bone strength and bone biochemical markers. We hoped that the results would serve as a useful reference to 
an exercise prescription.

\section{MATERIALS AND METHODS}

\section{Participants}

Sixty-eight marathoners who joined the marathon club ( 42 men and 26 women) and 40 controls (26 men and 14 women) who had not experienced any specific sports were recruited. In both groups, the ages ranged from 30 to 49 years. The average age of the marathoners was $39.2 \pm 5.1$ years, and that of controls was 37.6 \pm 6.4 years. There was no statistical difference. The mean body mass index for the marathoners was $25.6 \pm 2.8$, and for controls, $26.8 \pm$ 3.4 , there was no statistical difference between the two groups. Marathon runners had at least 6 months of exercise and the average period was 2 years, running at $48.6 \pm 24.9 \mathrm{~km}$ per week (Table 1). Approval for the study was obtained from the Institutional Review Board of Dong-A University (No. 18-068), and written consent was received from all participants.

\section{Measurements}

\section{Bone strength}

The bone strength was measured by quantitative ultrasound (QUS), Sunlight Omnisense device (Sunlight Medical Ltd., Tel Aviv, Israel). Bone speed of sound (SOS) was measured using QUS. SOS is based on the fact that ultrasonic waves travel faster in the bone than in the cartilage tissue, measured by moving the probe vertically to the end of the bone to find the maximum sound velocity. The measurement was performed at the distal third of the radius and at the center of the tibia. The radial and tibial velocities were measured three times and the mean value was considered as the results.

\section{Bone biochemical markers}

A blood test was conducted for the measurement of the osteocalcin (bone formation marker) and urine test for measurement of deoxypyridinolin (bone resorption marker). The osteocalcin was measured using the OSCA test Osteocalcin (BRAHMS Diagnostica, Berlin, Germany). The deoxypyridinolin was evaluated using

Table 1. Training characteristics in marathoners

\begin{tabular}{lcc}
\hline Variable & Mean \pm SD & Range \\
\hline Period of exercise $(\mathrm{mo})$ & $25.9 \pm 13.1$ & $6-60$ \\
Running distance per week $(\mathrm{km})$ & $48.6 \pm 24.9$ & $30-80$ \\
Frequency per week & $4.4 \pm 1.8$ & $1-7$ \\
\hline
\end{tabular}

$\mathrm{SD}$, standard deviation. the Pyrilinks-D kit (Metra Biosystems Co., Mountain View, CA, USA). To exclude the effects of changes in concentration in urine, the results of deoxyridrinolin were corrected with the creatinine value $(\mathrm{mM})$ of each specimen.

\section{RESULTS}

\section{Bone strength of the tibia}

The SOS of the tibia of men in their 30s showed 3,961.85 \pm $84.31 \mathrm{~m} / \mathrm{sec}$ in the marathon group and $3,920.90 \pm 56.87 \mathrm{~m} / \mathrm{sec}$ in the control group. There was no significant difference between the two groups $(P>0.05)$ (Fig. 1). There was no statistical difference in the SOS of the tibia of men in their 40s at 3,946.89 \pm $87.29 \mathrm{~m} / \mathrm{sec}$ in the marathon group and $3,920.33 \pm 98.91 \mathrm{~m} / \mathrm{sec}$ in the control $(P>0.05)$ (Fig. 1). The SOS of the tibia in women in their 30s was 3,929.0 $\pm 109.0 \mathrm{~m} / \mathrm{sec}$ in the marathon group and $3,879.0 \pm 84.46 \mathrm{~m} / \mathrm{sec}$ in the control group. In women in their 40s, the marathon group showed 3,848.0 $\pm 82.13 \mathrm{~m} / \mathrm{sec}$ and the control group showed $3,878.4 \pm 92.83 \mathrm{~m} / \mathrm{sec}$. There were no significant differences between the groups in both of $30 \mathrm{~s}$ and $40 \mathrm{~s}$ $(P>0.05)$ (Fig. 1).

\section{Bone strength of the radius}

The SOS of the radius of men in their 30s showed 4,136.85 \pm $115.05 \mathrm{~m} / \mathrm{sec}$ in the marathon group and 4,086.09 $\pm 95.01 \mathrm{~m} / \mathrm{sec}$ in the control group. The SOS of the radius of men in their $40 \mathrm{~s}$ showed 4,145.03 $\pm 139.66 \mathrm{~m} / \mathrm{sec}$ in the marathon group and $4,162.9 \pm 112.98 \mathrm{~m} / \mathrm{sec}$ in the control group. There were no significant differences between the groups in both of $30 \mathrm{~s}$ and $40 \mathrm{~s}$ $(P>0.05)$ (Fig. 2). The SOS of the tibia in women in their $30 \mathrm{~s}$ was $4,143.57 \pm 158.93 \mathrm{~m} / \mathrm{sec}$ in the marathon group and 4,177.1 \pm

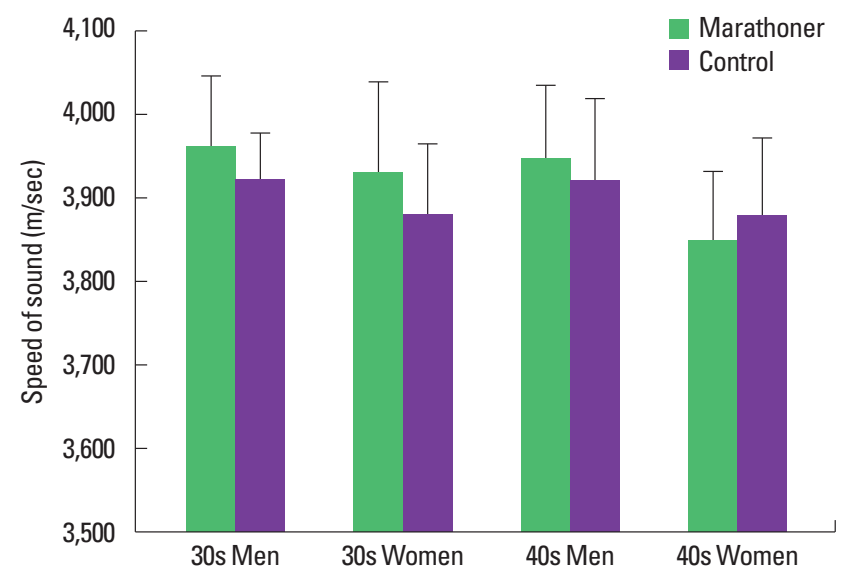

Fig. 1. Mean tibial speed of sound in the marathoner and control. 


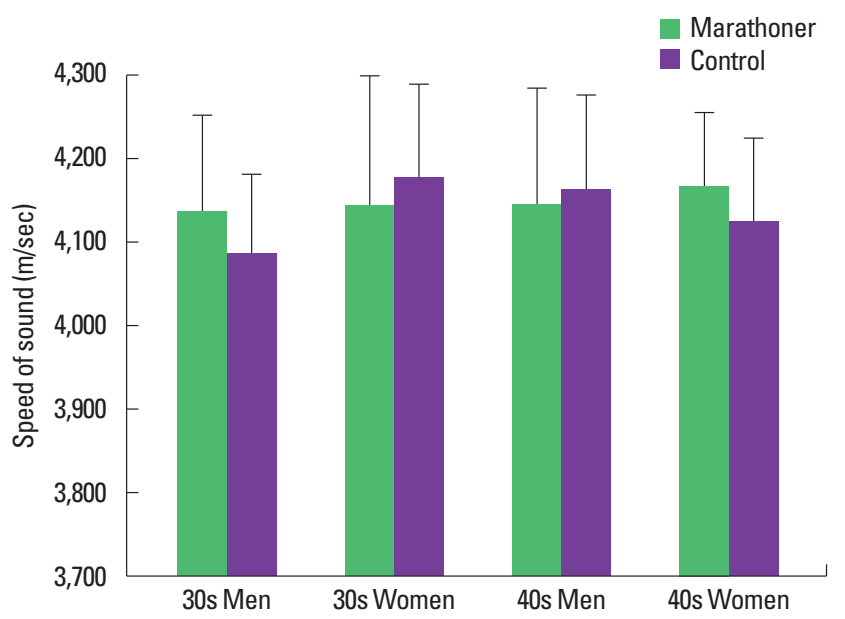

Fig. 2. Mean raidal speed of sound in the marathoner and control.

$112.56 \mathrm{~m} / \mathrm{sec}$ in the control group. In women in their 40s, the marathon group showed $4,166.8 \pm 87.76 \mathrm{~m} / \mathrm{sec}$ and the control group showed $4,124.3 \pm 100.11 \mathrm{~m} / \mathrm{sec}$. There were no significant differences between the groups in both of $30 \mathrm{~s}$ and $40 \mathrm{~s}(P>0.05)$ (Fig. 2).

\section{Bone biochemical markers}

There was a significant difference in blood osteocalcin of men in their 30s, with $11.24 \pm 4.19 \mathrm{ng} / \mathrm{mL}$ in the marathon group and $7.04 \pm 2.02 \mathrm{ng} / \mathrm{mL}$ in the control group $(P<0.05)$. There was a statistical difference in blood osteocalcin of men in their $40 \mathrm{~s}$, with $11.84 \pm 4.88 \mathrm{ng} / \mathrm{mL}$ in the marathon group and $7.17 \pm 1.86 \mathrm{ng} / \mathrm{mL}$ in the control group $(P<0.05)$. The blood osteocalcin of women in their 30s was $11.61 \pm 4.93 \mathrm{ng} / \mathrm{mL}$ in the marathon group and $5.04 \pm 2.47 \mathrm{ng} / \mathrm{mL}$ in the control group. In women in their $40 \mathrm{~s}$, the marathon group showed $10.34 \pm 4.06 \mathrm{ng} / \mathrm{mL}$ and the control group showed $6.51 \pm 2.99 \mathrm{ng} / \mathrm{mL}$. There were significant differences between the groups in both of 30s and 40s $(P<0.05)$ (Table 2).

There was no significant difference in urine deoxypyridinolin of men in their 30s, with $2.97 \pm 1.35 \mathrm{nM} / \mathrm{mM} \mathrm{Cr}$ in the marathon group and $3.24 \pm 1.43 \mathrm{nM} / \mathrm{mMCr}$ in the control group $(P>0.05)$. In men in their 40s, the marathon group showed $2.98 \pm 1.69 \mathrm{nM} /$ $\mathrm{mM} \mathrm{Cr}$ and the control group showed $2.05 \pm 1.51 \mathrm{nM} / \mathrm{mM} \mathrm{Cr}$. There was no significant difference between the two groups $(P>$ $0.05)$. The urine deoxypyridinolin of women in their 30 s was $4.9 \pm$ $2.60 \mathrm{nM} / \mathrm{mM} \mathrm{Cr}$ in the marathon group and $5.86 \pm 3.39 \mathrm{nM} / \mathrm{mM}$ $\mathrm{Cr}$ in the control group. In women in their 40 s, the marathon group showed $4.02 \pm 0.84 \mathrm{nM} / \mathrm{mM} \mathrm{Cr}$ and the control group showed $5.37 \pm 2.69 \mathrm{nM} / \mathrm{mM} \mathrm{Cr}$. There were no significant differences between the groups in both of $30 \mathrm{~s}$ and $40 \mathrm{~s}(P>0.05)$ (Table 3$)$.
Table 2. The concentration of serum osteocalcin $(\mathrm{ng} / \mathrm{mL})$

\begin{tabular}{lcclcc}
\hline \multirow{2}{*}{ Age $(y r)$} & \multicolumn{2}{c}{ Male } & & \multicolumn{2}{c}{ Female } \\
\cline { 2 - 3 } \cline { 5 - 6 } & Marathoner & Control & & Marathoner & Control \\
\hline $30-39$ & $11.2 \pm 4.1^{*}$ & $7.0 \pm 2.0$ & & $11.6 \pm 4.9^{*}$ & $5.0 \pm 2.4$ \\
$40-49$ & $11.8 \pm 4.8^{*}$ & $7.1 \pm 1.8$ & & $10.3 \pm 4.0^{*}$ & $6.5 \pm 2.9$ \\
\hline
\end{tabular}

Values are presented as mean \pm standard deviation.

${ }^{*} P<0.05$.

Table 3. The concentration of urine deoxypyridinolin (nmol/nmol Cr)

\begin{tabular}{lcclcc}
\hline \multirow{2}{*}{ Age (yr) } & \multicolumn{2}{c}{ Male } & & \multicolumn{2}{c}{ Female } \\
\cline { 2 - 3 } \cline { 5 - 6 } & Marathoner & Control & & Marathoner & Control \\
\hline $30-39$ & $2.9 \pm 1.3$ & $3.2 \pm 1.4$ & & $4.9 \pm 2.6$ & $5.8 \pm 3.3$ \\
$40-49$ & $2.9 \pm 1.6$ & $2.0 \pm 1.5$ & & $4.0 \pm 0.8$ & $5.3 \pm 2.6$ \\
\hline
\end{tabular}

Values are presented as mean \pm standard deviation.

\section{DISCUSSION}

Exercise is considered an important factor in preventing osteoporosis, but the mechanism of physical exercise on bone density is still unclear. According to Wolf's Law, bone shape and bone density depend on the forces acting on the bone (Krølner et al., 1983). In other words, if external pressure is applied to the bone, it is believed that an internal piezoelectricity will stimulate the osteoblast and induce new bone formation. Exercise also stimulates function of the osteoblast by promoting the release of growth hormones. During physical exercise, the level of plasma calcitonin can increase, which is thought to be a process of increasing bone mass (Aloia et al., 1985). According to Bennell et al. (1997), research of the weight-bearing exercise group, the long-distance running group and the normal control group showed that relatively wide increasing in the bone density of spine, radius and tibia of weight-bearing exercise group compared to normal controls. On the other hand, the long-distance running group only increased in the tibia compared to the control group. However, Hetland et al. (1993) reported that the bone mineral density of marathon runners who run more than $100 \mathrm{~km}$ per week decreased compared to normal controls. This was due to mechanical damage caused by long-distance running and inflammation of the bone tissue, resulting in increased bone metabolic rates and bone loss in the bone region under the most pressure.

In the marathon group for the general population evaluated in this study, there was no significant difference in the SOS of the tibia compared to the control group. These results can be explained by the mechanostat theory (Frost, 1987). When the strength of the workload is low, there is no effect on the bone metabolism and 
if more than a certain amount of load is applied, bone formation can be accelerated. However, a higher load is applied and exceeds a certain threshold the bone tissue can be impaired. MacDougall et al. (1992) showed that heavy long-distance runners had lower bone mineral content than normal population. This suggested that even in exercises that focused on endurance, greater intensity of exercise might have an adverse effect on the bone density. According to Huuskonen et al. (2001), changes in the bone density values of the femoral bones were not significant after three months of moderate aerobic exercise for the elderly aged 50 to 60 . Therefore, it is believed that the level of workload in marathon club, which runs $48 \mathrm{~km}$ per week, will not adversely affect bone density.

In this study, biochemical markers such as the osteocalcin and deoxypyridinolin were used to look at the effects of long-distance running on bone formation and absorption. Among the various bone marrow markers, one of the best indicators reflects bone formation is the blood osteocalcin. The basic structure is a $4.9-\mathrm{kD}$ peptide made of 46 amino acids that are produced from osteoblast and deposited in extracellular substances. Some of the newly synthesized osteocalcin is released into the blood, making it an indicator of the level of bone formation through measurements of the blood concentration (Lian and Gundberg, 1988). Osteocalcin is used for diagnosis and monitoring of the progress of treatment in various bone diseases, as it can reflect the conversion response of bone metabolism, particularly the activity of the osteoblast (Hauschka and Carr, 1982).

Urine deoxypyridinolin is a specific marker for bone absorption. It is a byproduct of collagen breakdown by osteoclast, which is not metabolized in vivo, and about $40 \%$ is excreted in free form and about $60 \%$ is in the form of peptide by urine. Urine deoxypyridinolin is known to almost come from bone and can be used as a highly specific bone absorption marker (Garnero and Delmas, 1996).

Both men and women had a higher blood osteocalcin level than controls in the marathon group in our study. This can be interpreted as proof of the hypothesis that moderate exercise promotes bone production. Other studies also have reported an increase level of blood osteocalcin from exercise (Casez et al., 1995; Lohman et al., 1995). Franck et al. (1991) reported that when young people performed exercise 2 to 3 times per week, osteocalcin level significantly decreased for first 4 weeks and 8 weeks later it was restored. In the early stages of exercise, the secretion of parathyroid hormone increases and the osteocalcin decreases. As adapt to training, bone formation can be stimulated and then continued. This shows that the period of exercise has a significant effect on the rate of bone metabolism. Woitge et al. (1998) conducted a comparative study of aerobic exercise and resistant exercise in relation to bone metabolism. In the aerobic exercise, the osteocalcin level decreased on the fourth week and then recovered for the eighth week, but the deoxypyridinolin continued to decrease. In the resistant exercise, the levels of osteocalcin and deoxypyridinolin increased for both 4 weeks and 8 weeks. As such, multiple factors like type, intensity, and duration of exercise have important effects on the rate of bone metabolism.

The results of urine deoxypyridinolin, measured in this study, did not yield a reduction in bone absorption markers as expected from an increase in bone formation markers from exercise. It was similar to research by Eliakim et al. (1997) that showed no significant difference in deoxypyridinolin after $2 \mathrm{hr}$ of regular exercise per day for 5 weeks conducting on teenagers. We cannot interpret these results accurately, but it is assumed that the strength and duration of the exercise were involved, as well as nutritional conditions and hormones. Kraemer et al. (2004) suggested that aerobic exercise like running has been shown to promote the release of growth hormones according to the strength of the exercise. According to the study of the relationship between growth hormones and bone metabolic rates conducted by Longobardi et al. (2000), an increase in the level of osteocalcin was observed after 84 days, but the level of deoxypyridinolin decreased for 42 days and then recovered at 84 days in the growth hormone administration group. These results may suggest that long-distance exercise will stimulate growth hormones, which are highly relevant to bone metabolism. However, since our study did not investigate the consequences of growth hormones, we think it will be necessary in the future.

Through this comparative study conducted on 68 marathoners and 40 normal controls, the following results were obtained: There was no significant difference between marathoners and normal controls in the SOS of the radius and tibia measured by QUS. A biochemical marker reflecting the bone formation, blood osteocalcin was significantly higher than the control in the marathon group, but there was no significant difference in a bone resorption marker, urine deoxypyridinolin between the two groups. As a result, long-distance running at the club level will increase bone formation markers, but will not have a detrimental effect on the properties of the bone.

\section{CONFLICT OF INTEREST}

No potential conflict of interest relevant to this article was reported. 


\section{ACKNOWLEDGMENTS}

This work was supported by the Dong-A University research fund.

\section{REFERENCES}

Aloia JF, Cohn SH, Babu T, Abesamis C, Kalici N, Ellis K. Skeletal mass and body composition in marathon runners. Metabolism 1978;27:17931796.

Aloia JF, Rasulo P, Deftos LJ, Vaswani A, Yeh JK. Exercise-induced hypercalcemia and the calciotropic hormones. J Lab Clin Med 1985;106:229232.

Bennell KL, Malcolm SA, Khan KM, Thomas SA, Reid SJ, Brukner PD, Ebeling PR, Wark JD. Bone mass and bone turnover in power athletes, endurance athletes, and controls: a 12-month longitudinal study. Bone 1997;20:477-484

Brahm H, Ström H, Piehl-Aulin K, Mallmin H, Ljunghall S. Bone metabolism in endurance trained athletes: a comparison to population-based controls based on DXA, SXA, quantitative ultrasound, and biochemical markers. Calcif Tissue Int 1997;61:448-454.

Casez JP, Fischer S, Stüssi E, Stalder H, Gerber A, Delmas PD, Colombo JP, Jaeger P. Bone mass at lumbar spine and tibia in young males--impact of physical fitness, exercise, and anthropometric parameters: a prospective study in a cohort of military recruits. Bone 1995;17:211-219.

Eliakim A, Raisz LG, Brasel JA, Cooper DM. Evidence for increased bone formation following a brief endurance-type training intervention in adolescent males. J Bone Miner Res 1997;12:1708-1713,

Franck H, Beuker F, Gurk S. The effect of physical activity on bone turnover in young adults. Exp Clin Endocrinol 1991;98:42-46.

Frost HM. Bone "mass" and the "mechanostat": a proposal. Anat Rec 1987; 219:1-9.

Garnero P, Delmas PD. New developments in biochemical markers for osteoporosis. Calcif Tissue Int 1996;59 Suppl 1:S2-9.

Hauschka PV, Carr SA. Calcium-dependent alpha-helical structure in osteocalcin. Biochemistry 1982;21:2538-2547.

Hetland ML, Haarbo J, Christiansen C. Low bone mass and high bone turnover in male long distance runners. J Clin Endocrinol Metab 1993; 77:770-775.

Huuskonen J, Väisänen SB, Kröger H, Jurvelin JS, Alhava E, Rauramaa R. Regular physical exercise and bone mineral density: a four-year controlled randomized trial in middle-aged men. The DNASCO study. Osteoporos Int 2001;12:349-355.

Kraemer RR, Durand RJ, Acevedo EO, Johnson LG, Kraemer GR, Hebert $\mathrm{EP}$, Castracane VD. Rigorous running increases growth hormone and insulin-like growth factor-I without altering ghrelin. Exp Biol Med (Maywood) 2004;229:240-246.

Krølner B, Toft B, Pors Nielsen S, Tøndevold E. Physical exercise as prophylaxis against involutional vertebral bone loss: a controlled trial. Clin Sci (Lond) 1983;64:541-546.

Kyröläinen H, Pullinen T, Candau R, Avela J, Huttunen P, Komi PV. Effects of marathon running on running economy and kinematics. Eur $\mathrm{J}$ Appl Physiol 2000;82:297-304.

Lian JB, Gundberg CM. Osteocalcin. Biochemical considerations and clinical applications. Clin Orthop Relat Res 1988;(226):267-291.

Lindberg JS, Fears WB, Hunt MM, Powell MR, Boll D, Wade CE. Exerciseinduced amenorrhea and bone density. Ann Intern Med 1984;101:647648.

Lohman T, Going S, Pamenter R, Hall M, Boyden T, Houtkooper L, Ritenbaugh C, Bare L, Hill A, Aickin M. Effects of resistance training on regional and total bone mineral density in premenopausal women: a randomized prospective study. J Bone Miner Res 1995;10:1015-1024.

Longobardi S, Keay N, Ehrnborg C, Cittadini A, Rosén T, Dall R, Boroujerdi MA, Bassett EE, Healy ML, Pentecost C, Wallace JD, Powrie J, Jørgensen JO, Saccà L. Growth hormone (GH) effects on bone and collagen turnover in healthy adults and its potential as a marker of $\mathrm{GH}$ abuse in sports: a double blind, placebo-controlled study. The GH2000 Study Group. J Clin Endocrinol Metab 2000;85:1505-1512.

MacDougall JD, Webber CE, Martin J, Ormerod S, Chesley A, Younglai EV, Gordon CL, Blimkie CJ. Relationship among running mileage, bone density, and serum testosterone in male runners. J Appl Physiol (1985) 1992;73:1165-1170.

Michel BA, Bloch DA, Fries JF. Weight-bearing exercise, overexercise, and lumbar bone density over age 50 years. Arch Intern Med 1989;149: 2325-2329.

Warren MP, Brooks-Gunn J, Fox RP, Lancelot C, Newman D, Hamilton WG. Lack of bone accretion and amenorrhea: evidence for a relative osteopenia in weight-bearing bones. J Clin Endocrinol Metab 1991;72: 847-853.

Westerterp KR, Meijer GA, Janssen EM, Saris WH, Ten Hoor F. Long-term effect of physical activity on energy balance and body composition. Br J Nutr 1992;68:21-30.

Williams JA, Wagner J, Wasnich R, Heilbrun L. The effect of long-distance running upon appendicular bone mineral content. Med Sci Sports Exerc 1984;16:223-227.

Woitge HW, Friedmann B, Suttner S, Farahmand I, Müller M, SchmidtGayk H, Baertsch P, Ziegler R, Seibel MJ. Changes in bone turnover induced by aerobic and anaerobic exercise in young males. J Bone Miner Res 1998;13:1797-1804. 